\title{
DEMOGRAPHIC RISK AND SOCIAL SUSTAINABILITY OF THE PENSION SYSTEM
}

\author{
Alexander Nepp, ${ }^{1} \mathrm{James}$ Okrah ${ }^{2}$
}

\begin{abstract}
In the framework of this study, we have obtained a mathematical model for maintaining the financial sustainability of PAYG pension systems. We introduce the term financial soundness, by which we understand the maintenance of a balance between the contributions to the pension system and the costs of pension payments. We have proved that the financial sustainability of PAYG systems depends on the growth rates of wages, the growth rate of contribution rates. And demographic factors such as the ratio of the number of pensioners and the working population. However, in the context of countries' competition for investment and the impossibility of increasing the rates of contributions to the pension system, as well as the limited business opportunities to increase wages, the financial sustainability of PAYG systems is determined only by demographic factors. Financial stability in such conditions is violated in case of excess of the rate of increase in pension payments over the rates of Support Ratio (ratio of working population and pensioners
\end{abstract}

JEL Classification Numbers: D53 G28; DOI: http://dx.doi.org/10.12955/cbup.v5.980

UDC Classification: 336

Keywords: Demographic risks, retirement age, PAYG, Pension payment, Support Ratio, Finance sustainability, Social sustainability

\section{Introduction}

The effect of demographic uncertainty on the pension system is strenuous to overestimate. Demographic uncertainty has consequences on the financial sustainability of the pension system by means of the earning and expenditure system. The basis of such effect is the age of entry, period work and the time of retirement, time span of saving, the number of employable citizens, number of retired citizens and the life expectancy,

Demographic Risk and its effect on the pension system has been discussed by many economists such as Wills (2010) and Cossette (2007). Fehr (2009) studied the effect of macro-economic uncertainty on the financial sustainability of the pension systems. His study showed that financial stability is based on two factors, the balance of income and expenditure in pension funds with acknowledgment to macroeconomic risk. Gurvich (2011) and Gurvich (2012), these two studies were focused on the impact of demographic risk on central indicators of the pension system.

The unique aspect of the work presented in this paper is the is the discussion of the way demographic uncertainty affect financial and social sustainability of the funded system and distribution

Financial sustainability of pension systems is defined as a balance between contributions to a pension system and pension payments. Apart from financial sustainability, this research also focused on the maintenance of social sustainability, which implies preservation of the core indicators of a pension system in the current conditions. Replacement rate is understood as the ratio of an average pension in a given time period and the average. It is considered to be the main indicator of the social sustainability of a pension system. This indicator was put forward by the International Labour Organization as the key characteristic of social sustainability (effectiveness) of pension systems. ${ }^{3}$

\section{Impact of demographic risks on financial and gregarious sustainability of distribution pension systems}

Demographic risks are important for distribution pension systems because they affect the amount of contributions through the number of payers, or the employed populations see Gurvich (2011). In his study, Volkov (2010) took into account such demographic risks as the number of employed people and that of retired people in the economy, as well as the number of people who enjoy certain benefits, when assessing Russia's implicit pension debt for the non-contributory part of the pension. This influence is tenacious by the following factors: 1) the amount of pension contributions depends on the number of employable people; 2) the amount of pension payments and the replacement rate are determined by the number of pensioners.

\footnotetext{
${ }^{1}$ Ural Federal University, Ekaterinburg, Russia, anepp@inbox.ru

${ }^{2}$ Ural Federal University, Ekaterinburg, Russia, jokrah6@gmail.com

${ }^{3}$ Official Website of the International Labour Organization. Access mode: www.ilo.org Last accessed date: 25.05.2013
} 
The impact of demographic risks on a distribution pension system can be presented mathematically as their impact on the core indicators of pension systems, the amount of pension payments (PV) and the replacement rate $(\mathrm{PZ})$.

$$
P V=\frac{P}{n}
$$

where:

$\mathrm{P}$ is the amount of contributions to the pension system;

$\mathrm{n}$ is the number of pensioners.

The amount of funds transferred to the distribution pension system from pension contributions can be presented the following way:

$$
P=Z p l *(1+r)^{i} * s^{*} k
$$

Where:

$\mathrm{Zpl}$ is an average salary;

$r$ is the average wage indexation rate;

$\mathrm{i}$ is the wage indexation period;

$\mathrm{s}$ stands for the pension contribution rates transferred to the distribution system;

$\mathrm{k}$ is a number of employed people who pay contributions.

Thus, if we plug the amount of pension contributions (formula (2)) into the formula (1), we get:

$$
P V=\frac{Z p l *(1+r)^{i} * s^{*} k}{n}
$$

The replacement rate, which shows the share of the pension (P) from the salary (Zpl) with regard to (3), will be calculated according to the following formula:

$$
P Z=\frac{Z p l *(1+r)^{i} * s^{*} k}{n} * \frac{1}{Z p l *(1+r)^{i}}=\frac{s^{*} k}{n}
$$

The dynamic impact of demographic risks on a distribution pension system is revealed through the changes of demographic parameters, such as the employed population and retired people, within a certain period of time: from year ' $j$ ' to year 'i.' It is crucial to point out that actuarial models making allowance for the impact of demographic risks on pension systems were developed by economists Kwon (2008), Debon (2008), who analyzed the impact of specific demographic factors on pension payments. However, their research does not consider the financial and social sustainability of pension systems. To analyze this factor, let us make the following transformations (4). The dynamics of pension payments, that is, the ratio of the pension payments in the year ' $\mathrm{j}$ ' to the pension payments in the year 'i,' is expressed with regard to (3) and (4) the following way:

$$
\frac{P V_{i}}{P V_{j}}=\frac{Z p l_{j}^{*}(1+r)^{i-j} * s_{i} * k_{i}}{n_{i}} \times \frac{n_{j}}{Z p l_{j} * S_{j} * k_{j}}=(1+r)^{i-j} \frac{S_{i}}{S_{j}} * \frac{k_{i}}{k_{j}} * \frac{n_{j}}{n_{i}}
$$

The expression (5) shows that the change of pension payments in distribution systems from the year ' $\mathrm{j}$ ' to the year ' $i$ ' will be determined by the average rate of wage indexation (r), the rate of insurance contributions (s), and the two demographic factors: the number of employed people (k) and the number of pensioners (n). In the conditions of economic stagnation and/or lack of increase in wages, we get the following formula by using the expression (5): 


$$
\left\{\begin{array}{l}
\frac{P V_{i}}{P V_{j}}==\frac{S_{i}}{S_{j}} \times \frac{k_{i}}{k_{j}} * \frac{n_{j}}{n_{i}} \\
r \rightarrow 0
\end{array}\right.
$$

The expression (6) demonstrates that when faced with demographic risks, that is, when the number of pensioners is growing $(\mathrm{ni}>\mathrm{nj})$ and the number of employed people is falling $(\mathrm{kj}>\mathrm{ki})$, the only way to maintain the level of pension payments is to provide the proportional growth of pension contribution rates $(\mathrm{Si}>\mathrm{Sj})$. Otherwise, pension payments will decrease.

In case of wages stagnation, however, or if it is infeasible or undesirable to increase the tax burden on enterprises due to the growth of pension contribution rates $(\mathrm{Si}=\mathrm{Sj})$, pension payments in distribution pension systems and their dynamics will be determined only by demographic factors, that is, the number of retired (n) and the number of employed people $(\mathrm{k})$ :

$$
\left\{\begin{array}{l}
\frac{P V_{i}}{P V_{j}}==\frac{k_{i}}{k_{j}} * \frac{n_{j}}{n_{i}} \\
r \rightarrow 0 \\
S_{i}=S_{j}
\end{array}\right.
$$

The systems (5) and (7) show that in a distribution pension system, an increase (or decrease) in pension payments used to maintain financial sustainability should not exceed the growth in the number of employed population and the fall in the number of pensioners provided that the insurance contribution rates and the wages remain the same. There is another option to be considered, though: if the number of the employed and retired remains the same (it is possible for short time periods), in order to maintain financial sustainability the growth in pension payments should not exceed the wages indexation provided that there is no growth in insurance contribution rates.

The formulas (5) and (7) include the ratio of the number of the employed population and the number of pensioners, which is another demographic indicator of the support ratio (Kp). Studies in economic demography consider it as one of the indicators of demographic risks. Thus, the support ratio is calculated according to the formula:

$$
K p=\frac{k}{n}
$$

If we take into consideration the formula (8), the system (5) will look like this:

$$
\frac{P V_{i}}{P V_{j}}=(1+r)^{i-j} \frac{S_{i}}{S_{j}} * \frac{K p_{i}}{K p_{j}}
$$

If we plug (8) into the system (7), we will get the following:

$$
\left\{\begin{array}{l}
\frac{P V_{i}}{P V_{j}}==\frac{K p_{i}}{K p_{j}} \\
r \rightarrow 0 \\
S_{i}=S_{j}
\end{array}\right.
$$

Judging by the system (10), the dynamics of pension payments in distribution systems is determined only by the correlation of support ratios, if there is no increase in wages and the tax burden remains constant.

The second target indicator of pension systems, as it has been noted before, is the replacement rate. To find out the impact of demographic risks on the replacement rate, let us plug (8) into the equation (4) and calculate the balance of the replacement rate in the year ' $j$ ' and the year ' $i$. .' The expression will then look the following way:

$$
\frac{P Z_{i}}{P Z_{j}}=(1-r) \times \frac{l_{i}}{l_{j}} \times \frac{K_{i}}{K_{j}} \times \frac{R_{i}}{R_{j}}=(1-r) \times \frac{I_{i}}{I_{j}} \times \frac{k p_{i}}{k p_{j}}
$$


Thus, the pension contribution rate (s), the number of employed people $(\mathrm{k})$, and the number of pensioners (n), that is will determine the dynamics of the replacement rate, by the support ratio (Kp). It is evident that for the replacement rate two out of the three major factors are demographic ones as distinct from the amount of pension payments (PV), which have two demographic factors out of the four influential ones. As a result, it can be concluded that in case of negative dynamics of demographic indicators, the only factor which makes it possible to maintain the support ratio will be the pension contribution rate, that is, the tax burden on enterprises, which is proven by the following expression (12):

$$
\left\{\begin{array}{l}
\frac{P Z_{i}}{P Z_{j}}==\frac{K p_{i}}{K p_{j}} \\
S_{i}=S_{j}
\end{array}\right.
$$

\section{Impact of demographic risks on the financial and social sustainability of funded pension systems. Theoretical framework}

The impact of demographic risks on funded pension systems is resolute by the following factors: 1) the amount of accumulated pension capital (pension savings) is tenacious inter alia by the accumulation period, that is, the age of starting working life and the retirement age; 2) the value of pension benefits depends on the endowment period, that is, the retirement age and the age.

The impact of demographic risks on the funded pension system can be represented by a mathematical formula through their influence on the fundamental parameters of pension systems: the value of pension payments $(\mathrm{PV})$ and the replacement rate $(\mathrm{PZ})$.

$$
P V=\frac{P n}{d}
$$

where:

Pn is the sum of pension savings;

$\mathrm{d}$ is the endowment period

The amount of pension savings can be expressed in terms of wages, the rate of indemnification contributions, and the accumulation period:

$$
P n=\sum_{q=1}^{w-v} s n \times Z p l \times((1+r) \times(1+a))^{q}=s \times Z p l \times \sum_{i=1}^{w-v}\left((1+r) \times(1+a)^{q}\right.
$$

where:

$\mathrm{Zpl}$ - the average wage;

$r$ - an average rate of wage indexation;

$q$ - a period of wage indexation and investment period;

sn - the rate of indemnification contributions directed to the funded system;

a - rate of investment income (in shares) received from the investment of pension savings;

$\mathrm{w}$ - retirement age;

$\mathrm{v}$-age of ingress into working life. In turn, the endowment period is determined by the age of retirement (retirement age) (w) and the expected life span (z):

$$
d=z-w
$$

Thus, by substituting (14) and (15) into (13), we obtain the following formula

$$
P V=\frac{s \times Z p l \times \sum_{q=1}^{w-}((1+r) \times(1+a))^{q}}{z-w}
$$

characterizing the share of lost earnings replaced by pension payments. The replacement rate will be calculated accordingly: 


$$
\left\{\begin{array}{l}
\frac{P V_{i}}{P V_{j}}=\frac{\left.\sum_{q=1}^{w_{i}-v_{i}}\left(1+a_{i}\right)\right)^{q}}{z_{i}-w_{i}} \times \frac{z_{j}-w_{j}}{\sum_{q=1}^{w_{j}-v_{j}}\left(1+a_{j}\right)^{q}} \\
r \rightarrow 0 \\
Z p l_{i}=Z p l_{j} \\
S_{i}=S_{j}
\end{array}\right.
$$

As it is demonstrated by the obtained formulae for the main indicators of the pension systems, pension payments (16), the impact of demographic risks in a funded pension system will be largely offset by the investment income, the effect of which is amplified by a function exponent.

The dynamic impact of demographic risks is defined through pension benefits under a funded pension system for the years ' $i$ ' and ' $\mathrm{j}$ ' and the coefficient of the main indicators of a funded pension system:

$$
\frac{P V_{i}}{P V_{j}}=\frac{s_{i} \times Z p l_{i} \times \sum_{q=1}^{w_{i}-v_{i}}\left(\left(1+r_{i}\right) \times\left(1+a_{i}\right)\right)^{q}}{z_{i}-w_{i}} \times \frac{z_{j}-w_{j}}{s_{j} \times Z p l_{j} \times \sum_{q=1}^{w_{j}-v_{j}}\left(\left(1+r_{j}\right) \times\left(1+a_{j}\right)^{q}\right.}
$$

As it can be optically discerned from the formula (18), the impact of demographic risks on pension payments, namely the age of ingress into the labor market, the retirement age, and life expectancy, will be largely constrained by the investment income, the effect of which is amplified by the function exponent.

If there is no magnification in wages, the dynamics of pension payments in a funded pension system depends on the rate of indemnification contributions (s), rates of investment income (a,) and certain demographic parameters: the retirement age (w), the age of ingression into working life (v), and life expectancy (z). However, utilizing the rate of indemnification contributions as a factor-effect to increment pension payments to a funded pension system would authentically mean an incrementation in the tax burden on enterprises. Consequently, when it is infeasible or undesirable to increment the tax burden, the investment income and demographic factors will only influence pension payments:

$$
P Z=\frac{P V}{Z p l \times(1+r)^{w-v}}=\frac{s \times Z p l \times \sum_{q=1}^{w-\mu}((1+r) \times(1+a))^{q}}{z-w} \times \frac{1}{Z p l \times(1+r)^{w-v}}=\frac{s \times \sum_{q=1}^{w-v-1}(1+r)^{q} \times \sum_{q=1}^{w-v}(1+a)^{q}}{z-w}
$$

It should be noted that this issue has been described, for example by Gontmakher (2012). In the formula (7), the difference in life expectancy $(\mathrm{z})$ and the retirement age (w) is the duration of pension payments (tv); while the difference of retirement age (w) and the age of ingression into working life (v) is the period of pension savings (tn). Retirement payments under a funded pension system are less susceptible to demographic risks compared with pension payments within the distribution system, as under the funded pension system the function exponent of the investment income can handle them. If there is a task of constructing a financially sustainable funded pension system, it does not require eliminating the impact of demographic risks by the investment income $(a=0)$, we achieve financial sustainability of a funded pension system under the influence of demographic risks the following way:

$$
\left\{\begin{array} { c } 
{ \frac { P V _ { i } } { P V _ { j } } = \frac { t _ { n _ { i } } } { t _ { n _ { j } } } \times \frac { t _ { v _ { j } } } { t _ { v _ { i } } } } \\
{ P V _ { i } \geq P V j } \\
{ \frac { t _ { n _ { i } } } { t _ { n _ { j } } } \geq \frac { t _ { v _ { i } } } { t _ { v _ { j } } } }
\end{array} \text { or } \quad \left\{\begin{array}{c}
P V_{i}=\frac{t_{n_{i}}}{t_{n_{j}}} \times \frac{t_{v_{j}}}{t_{v_{i}}} \\
P V_{i} \geq P V \\
\Delta t_{n} \geq \Delta t_{v}
\end{array}\right.\right.
$$


Maintenance of pension payments at the current level and at the same time dealing with demographic risks, provided there is no growth of wages and investment income, is possible if the increase in the duration of pension savings exceeds that of pension distributions. It is also possible in the following situation: while the duration of the pension savings period and that of the pension distribution period are both becoming shorter, the rates of the former process should be going at a slower pace than the latter.

However, the advantage of funded pension systems as compared with the distribution ones lies in the fact that the impact of demographic risks on the former can be offset by the investment income, but not only due to the growing tax burden through incremented indemnification payments. Hence, there is a second option available to maintain the stability of a funded pension system. If the system experiences a negative impact of demographic jeopardies, for instance, in the situation of more expeditious magnification in the duration of the retirement period as compared to the duration of the working life, then pension payments will still remain identically tantamount, provided that the impact of investment income through the function exponent is more vigorous or if there is an incrementation in the rates of indemnification payments.

Thus, the compulsory precondition for the conservation of the supersession rate as well as pension payments in funded pension systems is primarily the transmutation in the duration of pension savings rather than in that of pension payments.

Growing demographic risks affect not only the Russian pension system: they make one of the major challenges faced by OECD countries' pension systems (optically discern Maclnes, 2003).

\section{Conclusion}

1.In a distribution pension system, an increase (or reduction) in pension payments to maintain financial sustainability should not exceed the growth in the number of working population and the decrease in the number of pensioners (provided that the rate of insurance contributions remains the same). If the number of working population and that of retired citizens remains the same (which is possible for short time periods), then the growth (reduction) in pension payments should not exceed the indexation of wages.

2. Funded pension systems are under the influence of demographic risks to a lesser degree than the alternative distribution systems;

3. The following precondition for financial sustainability of funded pension systems is proposed: the dynamics of pension payments and the supersession rate should not exceed the dynamics of indemnification payment rates, the rates of the investment income, duration of savings and payments.

\section{References}

Peter Auer, Mariàngels Fortuny Employment paper. Ageing of the Labour Force in OECD Countries: Economic and Social Consequences. International Labour Office Geneva. Employment Sector. 2000. $51 \mathrm{p}$

Cossette, H, Delwarde, A., Denuit, M., Guillot, F., Marceau, E.T. (2007) Pension Plan Evaluation and Mortality Projection: A Case Study with Mortality Data//North American Actuarial Journal. Volume 11, Issue 2, -April 2007, P. 1-34

Debón, A., Montes, F., Puig, F. (2008) Modelling and Forecasting Mortality in Spain//European Journal of Operational Research. Volume 189, Issue 3, 16 September 2008, P. 624-637

Fehr, H. (2009) Computable Stochastic Equilibrium Models and Their Use in Pension-and Ageing Research//Economist. Volume 157, Issue 4, 2009, P. 359-416

Gontmakher E. (2012) Problem of Population Aging in Russia / / World Economy and International Relations. 2012. No 1. P. 22-29

Gurvich E.T., Sonina Y.V. (2012) Microanalysis of the Russian Pension System// Voprosy Ekonomiki. 2012. № 2. P. 27-51 Gurvich E.T. (2011) Principles of the New Pension Reform// Voprosy Ekonomiki. 2011. № 4. 4-32 p.

Kwon, S. (2008) Future of Long-Term Care Financing for the Elderly in Korea// Journal of Aging and Social Policy. Volume 20, Issue 1, 2008, P. 119-136

Maclnnes J. (2003). Sociology and Demography: A Promising Relationship? Women's Employment, Parental Identity and Fertility in Europe. An Analysis of the Family and Gender Roles // Edinburgh Working Papers in Sociology. No 23 / University of Edinburgh.

Wills, S., Sherris, M. (2010) Securitization, Structuring and Pricing of Longevity Risk//Insurance: Mathematics and Economics. Volume 46, Issue 1, February 2010, Pages 173-185

Volkov Y. (2010) Results of Assessment of Russia's Implicit Pension Debt// Voprosy Ekonomiki, № 5, May 2010, P. 123-137 